\title{
Mammografia 3D z tomosyntezą. Kontrola jakości - regulacje prawne i metodyka pomiaru średniej dawki gruczołowej.
}

\section{D mammography with tomosynthesis. Quality Assurance - legal regulations and methodology of average glandular dose measurements.}

\author{
Krzysztof Matuszewski ${ }^{1}$, Piotr Romański ${ }^{1}$ \\ ${ }^{1}$ Zakład Fizyki Medycznej, Wielkopolskie Centrum Onkologii, Poznań, Polska
}

\section{Streszczenie}

Mammografia trójwymiarowa ( $\mathrm{z}$ ang. three-dimensional; 3D) z tomosyntezą jest efektem rozwoju technologii w obrazowaniu na przestrzeni ostatnich kilku dekad. Skutkiem tego jest wzrost czułości badań mammograficznych, będący czynnikiem prowadzącym do zwiększenia wykrywalności nowotworów piersi. Jednym z elementów warunkujących utrzymanie wysokiej czułości mammografii jest kontrola jakości urządzeń stosowanych w mammografii z tomosyntezą. Celem niniejszego artykułu jest opis regulacji prawnych dotyczących kontroli jakości urządzeń stosowanych w mammografii 3D z tomosyntezą oraz metodologia pomiaru średniej dawki gruczołowej

\begin{abstract}
3D mammography with tomosynthesis is the effect of technology development in imaging over the last few decades. The result of this development is the increase the diagnostic sensitivity of mammography, which is a factor leading to increased detection of breast cancer. One of the elements determining the high sensitivity of mammography is the quality control. The aim of this article is to describe the legal regulations concerning the quality control of devices used in 3D mammography with tomosynthesis and the methodology of measuring average glandular dose.
\end{abstract}

Słowa kluczowe: mammografia 3D, tomosynteza, średnia dawka gruczołowa, kontrola jakości

Keywords: 3D mammography, tomosynthesis, average glandular dose, quality assurance

Adres do korespondencji

Krzysztof Matuszewski

Zakład Fizyki Medycznej,

Wielkopolskie Centrum Onkologii, ul. Garbary 15, 61-866 Poznań, Polska

Telefon. +488850552

e-mail: krzysztof.matuszewski@wco.pl 


\section{Wstęp}

Mammografia jest badaniem obrazowym wykorzystywanym do wykrywania patologii piersi, w szczególności nowotworów złośliwych [1]. W 2007 r. w ramach Narodowego Programu Zwalczania Chorób Nowotworowych rozpoczęto krajowy program badań przesiewowych - Populacyjny Program Wczesnego Wykrywania Raka Piersi [2]. Badania mammograficzne przeprowadzane w ramach tego programu służą do wykrywania raka sutka. Jednym z czynników, mających wpływ na poprawę wykrywalności raka gruczołu sutkowego w ciągu ostatnich kilku dekad, jest postęp technologiczny, który doprowadził do wzrostu czułości mammografii.

Początkowo badania mammograficzne wykonywane były z zastosowaniem filmów radiograficznych umieszczonych w kasetach pozbawionych ekranów wzmacniających. Skutkowało to dostarczaniem wysokich dawek promieniowania jonizującego podczas badania i otrzymywaniem zaszumionych obrazów o niskim kontraście. W latach 70. i na początku lat 80. XX wieku bardzo popularna stała się mammografia wykorzystująca proces kserograficzny. Cechowała się stosunkowo wysoką rozdzielczością przestrzenną. Jednak po wprowadzeniu do użycia ekranów wzmacniających w kasetach stosowanych w mammografii analogowej została przez nią wyparta. Efektem dalszego rozwoju było wprowadzeniem systemów cyfrowych w mammografii do użytku klinicznego już na początku XXI wieku $[1,3]$. Nowe algorytmy przetwarzania obrazów, dające możliwość obrazowania i rekonstrukcji trójwymiarowej, znanej między innymi z tomografii komputerowej czy rezonansu magnetycznego, stały się fundamentem mammografii 3D z tomosyntezą. Wraz z postępem technologicznym nastąpił znaczny wzrost przydatności obrazów otrzymywanych w badaniach mammograficznych do celów diagnostycznych (Ryc. 1.).
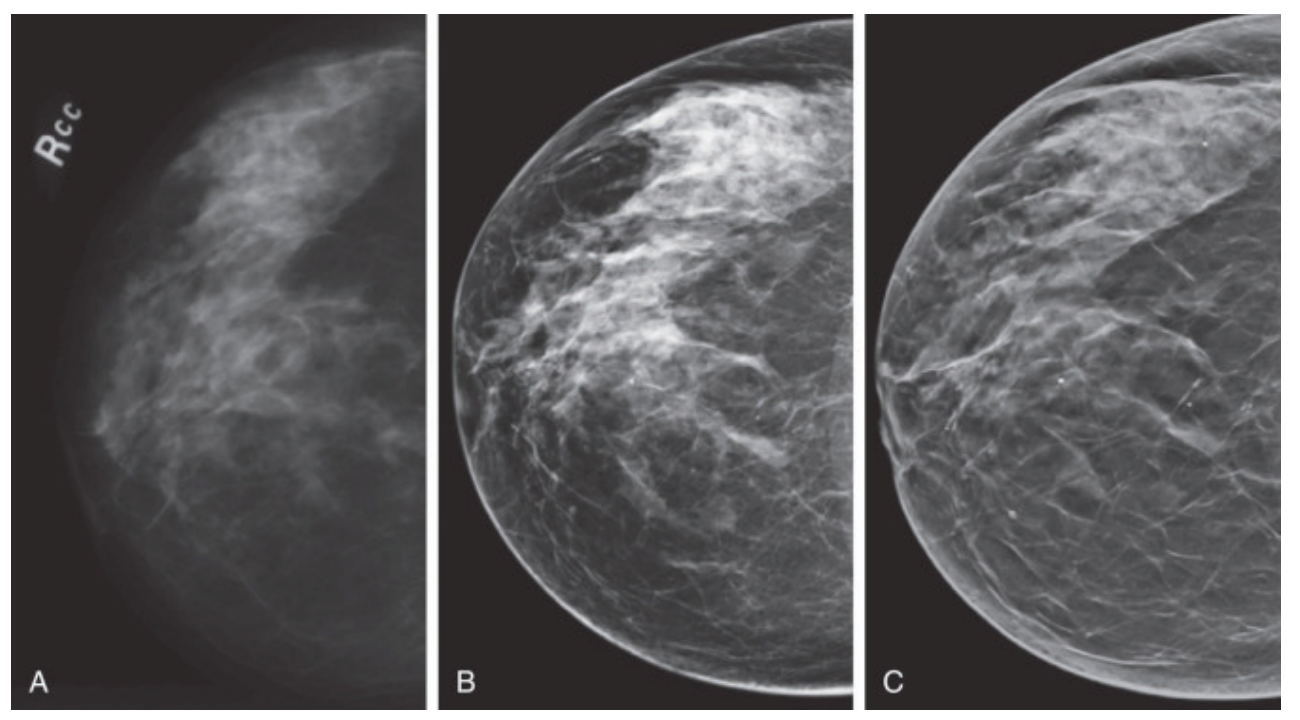

Ryc. 1. Postęp w mammografii. Projekcja kraniokaudalna piersi w mammografii analogowej (A), mammografii cyfrowej (B) i mammografii 3D z tomosyntezą (C) [4].

\section{Mammografia cyfrowa $3 D$ z tomosyntezą}

Koncepcję tomosyntezy w mammografii opisano po raz pierwszy w latach 60. XX wieku. Podstawowe zasady tomosyntezy zostały przeanalizowane przez Millera i wsp. w 1971 r. [5]. Pierwszy system do cyfrowej tomosyntezy piersi zbudowała firma GE Healthcare we współpracy z armią amerykańską [6]. W konwencjonalnej mammografii cyfrowej zarówno lampa rentgenowska, system kompresji gruczołu sutkowego oraz detektor pozostają nieruchome. W trakcie badania uzyskiwany jest dwuwymiarowy obraz. Piksele reprezentują informację uzyskaną z całej objętości gruczołu sutkowego. Jednym z głównych ograniczeń metody w konwencjonalnym obrazowaniu jest nakładanie się na siebie tkanek sutka, które mogą przysłaniać zmiany patologiczne zwiększając tym samym liczbę wyników fałszywie dodatnich [7].

W cyfrowej tomosyntezie piersi lampa rentgenowska zakreśla łuk (zwykle od $15^{\circ}$ do $50^{\circ}$ ) ruchem ciągłym lub skokowym, wykonując w tym czasie poszczególne ekspozycje (zwykle od 9 do 25; Tab.1.) [8,9]. 


\begin{tabular}{|l|c|c|c|}
\hline Nazwa systemu do tomosyntezy & Geometria skanowania & $\begin{array}{c}\text { Zakres } \\
\text { kątowy } \\
\text { projekcji [0] }\end{array}$ & $\begin{array}{c}\text { Liczba } \\
\text { wykonywanych } \\
\text { projekcji }\end{array}$ \\
\hline GE Healthcare SenoClaire & bez kolimacji pola & 25 & 9 \\
\hline GE Healthcare Pristina & bez kolimacji pola & 25 & 9 \\
\hline Hologic Selenia Dimension & bez kolimacji pola & 15 & 15 \\
\hline IMS Giotto TOMO & bez kolimacji pola & 40 & 13 \\
\hline IMS Giotto Class & bez kolimacji pola & 30 & 11 \\
\hline Philips Microdose & z kolimacją pola & N/A & $21^{\mathrm{B}}$ \\
\hline Planmed Clarity3D & bez kolimacji pola & 30 & 15 \\
\hline Siemens Mammomat Inspiration & bez kolimacji pola & 50 & 25 \\
\hline Fujifilm Amulet Innovality & bez kolimacji pola & $15 / 40$ & 15 \\
\hline $\begin{array}{l}\text { A - ruch lampy rentgenowskiej w zakresie 34 } \\
\text { B - system rejestruje 21 zestawów danych z linii detektora. }\end{array}$ & & \\
\hline
\end{tabular}

Tab. 1. Specyfikacja i opis geometrii stosowanej w dostępnych systemach do tomosyntezy piersi (opracowanie własne na podstawie [9]).

W tomosyntezie skanowanie gruczołu piersiowego może odbywać się wiązką pokrywającą cały detektor (Ryc. 3A.), podobnie jak w konwencjonalnej mammografii 2D lub przy użyciu skolimowanej wiązki promieniowania (Ryc. 3B.) z jednoczesnym ruchem lampy rentgenowskiej i detektora.

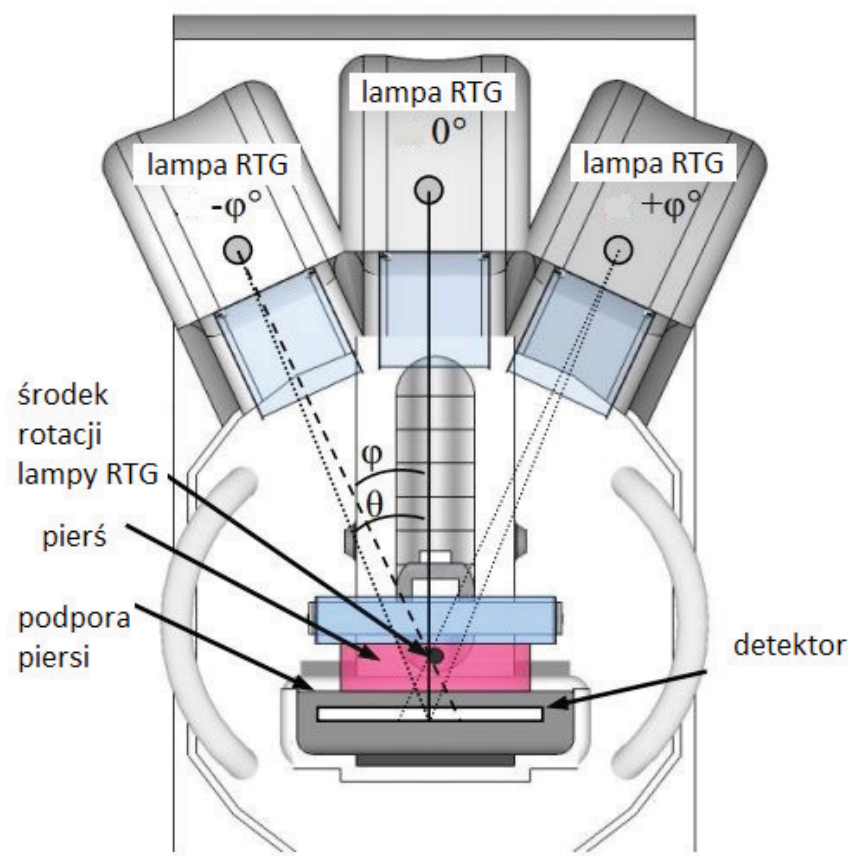

Ryc. 3A. Schemat systemu do tomosyntezy piersi z geometrią pola promieniowania pokrywającego cały detektor. $\theta$ - kąt projekcji, $\varphi$ - kąt rotacji lampy rentgenowskiej [9].

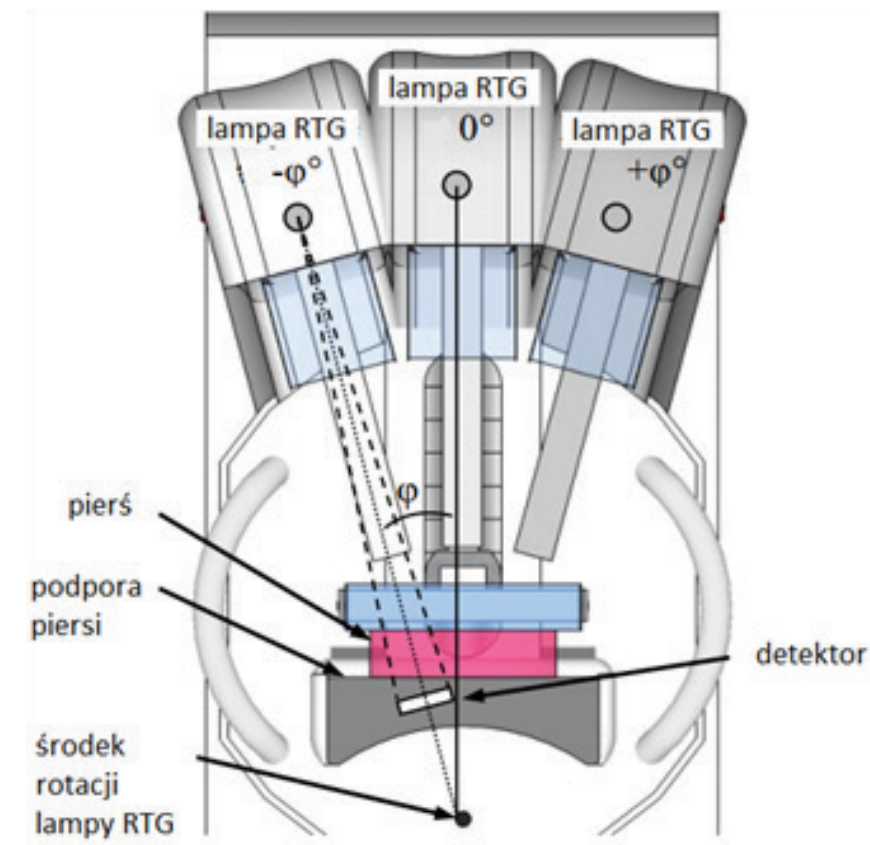

Ryc. 3B. Schemat systemu do tomosyntezy piersi z geometrią skolimowanego pola promieniowania. $\varphi$ - kąt rotacji lampy rentgenowskiej [9]. 


\section{Regulacje prawne dotyczące kontroli jakości w mammografii 3D z tomosyntezą}

Zgodnie z obowiązującymi w Polsce regulacjami prawnymi, dokumentami obligującymi do prowadzenia kontroli jakości urządzeń radiologicznych są: ustawa Prawo Atomowe (Obwieszczenie Marszałka Sejmu Rzeczypospolitej Polskiej z dnia 23 marca 2018 r., Dz.U.2018. poz. 792) oraz Rozporządzenie Ministra Zdrowia w sprawie warunków bezpiecznego stosowania promieniowania jonizującego dla wszystkich rodzajów ekspozycji medycznej (Obwieszczenie Ministra Zdrowia z dnia 3 kwietnia 2017 r., Dz.U.2017. poz. 884). Ostatni dokument zawiera wykaz testów podstawowych oraz specjalistycznych, jakim podlegają urządzenia radiologiczne wraz częstotliwością ich wykonywania oraz kryteriami jakie muszą spełniać. Regulacje te obejmują również testy dotyczące urządzeń stosowanych w mammografii analogowej i cyfrowej. Rozporządzenie to nie reguluje jednakże zasad kontroli jakości aparatury służącej mammografii 3D z tomosyntezą.

Należy wrócić uwagę na treści zawarte w przepisach ogólnych Rozporządzenia Ministra Zdrowia, zgodnie z którymi, jeżeli stosowane urządzenia radiologiczne nie są wymienione w tym rozporządzeniu, to kontrolę fizycznych parametrów tych urządzeń należy przeprowadzać w zakresie oraz z częstotliwością, która wynika z norm polskich lub europejskich, zwalidowanych metod badawczych albo instrukcji producenta [10].

Coraz częściej producenci aparatów mammograficznych dostarczają podręczniki kontroli jakości, które stanowią element programu zapewnienia jakości placówek wykonujących badania mammograficzne.

Zgodnie z prawem obowiązującym w krajach Unii Europejskiej (UE), zalecenia dotyczące badań przesiewowych w mammografii, które znajdują zastosowanie zarówno w klasycznej mammografii analogowej, jak i cyfrowej, reguluje European Guidelines for Quality Assurance In Breast Cancer Screening and Diagnosis, opracowany i wydany przez European Reference Organisation for Quality Assured Breast Screening and Diagnostic Services (EUREF). Wytyczne dotyczące kontroli jakości w mammografii 3D z tomosyntezą zostały przedstawione w Protocol fot the Quality of the Physical and Technical Aspects of Digital Breast Tomosynthesis Systems (EUREF, marzec 2018) [11]. Obecnie korzysta się również z zaleceń amerykańskich dotyczących kontroli jakości urządzeń radiologicznych, które są tworzone głównie przez dwie wiodące instytucje American College of Radiology (ACR) oraz American Association of Physicist In Medicine (AAPM). Zalecenia ACR, dotyczące minimalnych standardów i kontroli jakości w mammografii, zostały wprowadzone już w latach 80. XX w. i przyczyniły się do poprawy bezpieczeństwa pacjentów poddawanych badaniom.

W 2016 r. ACR wydało nowy podręcznik kontroli jakości w mammografii cyfrowej nie ujmujący jednak szczegółowych zaleceń dla mammografii 3D z tomosyntezą. Zapisy w nim zawarte wskazują jedynie, że urządzenia te powinny być poddawane kontroli jakości zgodnie z zaleceniami obowiązującymi dla klasycznej mammografii cyfrowej rozszerzonej o procedury kontroli jakości zalecane przez producentów dla tomosyntezy [11]. Z uwagi na brak jednoznacznego opisu sposobu przeprowadzania kontroli jakości w mammografii z zastosowaniem tomosyntezy, wytyczne ACR nie uzyskały rekomendacji Amerykańskiej Agencji ds. Żywności i Leków (z ang. Food and Drug Administration; FDA).

\section{Metodyka pomiaru średniej dawki gruczołowej (z ang. Average Glangular Dose; ADG)}

Procedurapomiaruśredniejdawkigruczołowej,jakąotrzymujepacjentpodczasbadaniamammograficznego dla systemów cyfrowych z tomosyntezą jest rozszerzeniem procedury stosowanej w klasycznej mammografii 2D (szczegółowy opis procedury: Dance i wsp.) [12].

W mammografii 3D z tomosyntezą, średnia dawka gruczołowa jest sumą dawek, jakie pochodzą z poszczególnych projekcji wykonywanych w trakcie badania. Dawkę gruczołową dla poszczególnej projekcji przy kącie lampy rentgenowskiej $\theta$ można określić zależnością:

$$
\mathrm{D}(\theta)=\mathrm{K} \times \mathrm{g} \times \mathrm{c} \times \mathrm{s} \times \mathrm{t}(\theta)
$$

gdzie:

$\mathrm{D}(\theta)$ - dawka gruczołowa dla poszczególnej ekspozycji [Gy],

K - kerma (suma energii kinetycznej cząstek naładowanych, które powstają na skutek oddziaływania 
promieniowania jonizującego pośrednio (fotony, neutrony) w małym elemencie masy materiału) na powierzchni piersi nie uwzględniająca rozproszenia wstecznego, zmierzona dla kąta $0^{\circ}$ lampy rentgenowskiej dla obciążenia prądowo-czasowego mAs odpowiedniego dla ekspozycji wykonanej na kącie $\theta$ [Gy],

g - współczynnik korekcyjny uwzględniający grubość piersi po kompresji,

c - współczynnik korekcyjny uwzględniający skład tkankowy piersi,

s - współczynnik korekcyjny uwzględniający widmo promieniowania rentgenowskiego,

$\mathrm{t}(\theta)$ - współczynnik korekcyjny dla kąta projekcji w tomosyntezie.

Powyższa zależność, opisująca średnią dawkę gruczołową dla kąta projekcji $\theta=0^{\circ}$ znajduje zastosowanie

w AGD w klasycznej mammografii 2D.

Całkowitą średnią dawkę gruczołową w tomosyntezie można określić zgodnie z zależnością:

$$
D_{T}=K_{T} \times g \times c \times s \times T,
$$

gdzie: $T=\sum_{i} a_{i} t\left(\theta_{i}\right)$. Współczynnik ai określa część obciążenia prądowo-czasowego mAs przypadającą

na daną projekcję. Pomiaru kermy wykonuje się dla kąta $0^{\circ}$ lampy rentgenowskiej i dla całkowitego mAs pochodzącego ze wszystkich projekcji. Wartości współczynników g, c, s oraz t zostały wprowadzone przez Dance i wsp. Ich wykaz znajduje się w [9]. Należy jednak pamiętać, że wartości współczynnika t są funkcją kąta projekcji $\theta$, a nie kąta rotacji lampy rentgenowskiej $\varphi$. Pomiędzy kątami tymi zachodzi związek opisany równaniem:

$$
\varphi=\theta+\sin ^{-1}\left(\frac{d \sin \theta}{r}\right)
$$

gdzie:

d - odległość od środka rotacji do detektora [m],

r - odległość od ogniska lampy rentgenowskiej do środka rotacji [m].

W załączniku do dokumentu Protocol fot the Quality of the Physical and Technical Aspects of Digital Breast Tomosynthesis Systems przedstawiono wykaz wartości T dla dostępnych komercyjnie aparatów mammograficznych 3D z tomosyntezą. Powyższe zależności można wykorzystać do wyznaczenia średniej dawki gruczołowej dla systemów, w których pole promieniowania pokrywa cały detektor w trakcie ekspozycji (Ryc. 3A).

W przypadku aparatów mammograficznych wykorzystujących kolimatory wiązki promieniowania jonizującego (Ryc. 3B), w których obrazowany jest fragment piersi, obowiązuje zależność:

$$
D_{S}=K_{S} \times g \times c \times s \times T_{S}
$$

gdzie:

$\mathrm{K}_{\mathrm{S}}$ - kerma zmierzona dla pełnego skanowania [Gy],

$\mathrm{T}_{\mathrm{S}}$ - współczynnik korekcyjny dla pełnego skanowania w tomosyntezie.

Współczynnik TS jest zależny od umiejscowienia miernika dawki oraz od grubości piersi i wyznaczany dla geometrii każdego z systemów (dane tabelaryczne) [10, 12].

\section{Pomiar ADG z wykorzystaniem płyt PMMA symulujących pierśs}

Chcąc określić AGD w tomosyntezie z zastosowaniem fantomu wykonanego z płyt PMMA (polimetakrylan metylu) należy wykonać następujące czynności:

1. Wybrać tryb pracy aparatu mammograficznego i przeprowadzić obrazowanie fantomu PMMA 
o grubościach 20,30,40, 45, 50, 60 i $70 \mathrm{~mm} \mathrm{z}$ zastosowaniem tomosyntezy. Zapisać warunki ekspozycji dobrane przez system automatycznej kontroli ekspozycji (z ang. Automatic Exposure Control; AEC) aparatu.

2. Odczytać wartość współczynników g, c i s. Wartość współczynników g i c jest zależna od grubości warstwy półchłonnej (z ang. Half-Value Layer; HVL), dlatego jeżeli to konieczne wyznaczyć ich wartość poprzez interpolację dla zmierzonej HVL wykorzystując dane tabelaryczne [9, 12].

3. Dawkomierz umieścić na stoliku mammografu, $60 \mathrm{~mm}$ od strony klatki piersiowej, symetrycznie do krawędzi bocznych (Ryc. 4.). Dosunąć płytkę uciskową.

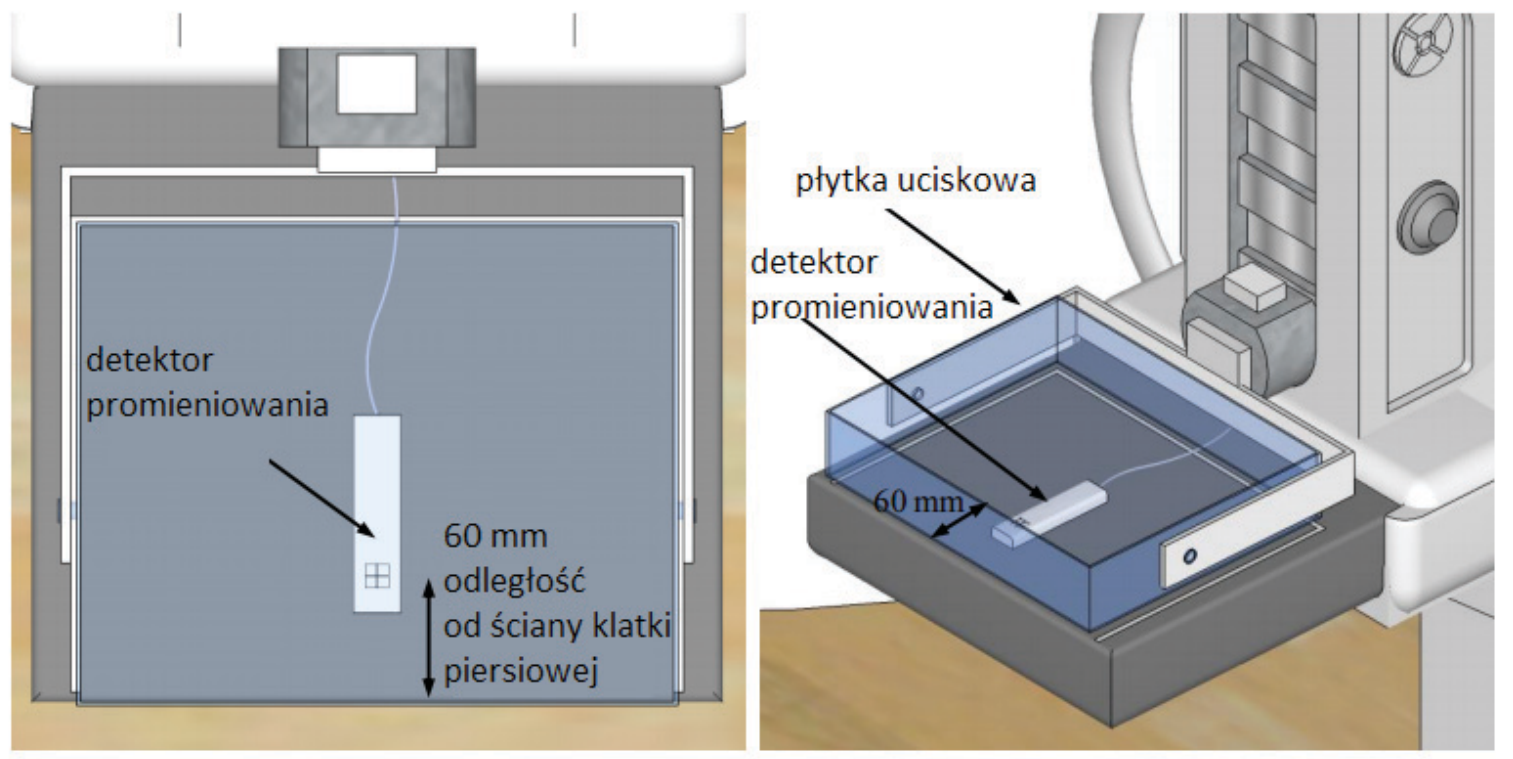

Ryc. 4. Pozycjonowanie detektora promieniowania do pomiaru kermy [8].

4. Zmierzyć kermę dla parametrów uzyskanych podczas eskpozycji fantomu z PMMA przy zachowaniu kąta $0^{\circ}$ lampy rentgenowskiej. W razie konieczności wybrać najbliższą dostępną na mammografie wartość obciążenia prądowo-czasowego.

5. Przeliczyć wartość zmierzonej kermy na powierzchni fantomu z PMMA.

6. Zastosować współczynniki do tomosyntezy T lub TS w zależności od testowanego systemu.

7. Porównać otrzymane wyniki z wartościami dopuszczonymi przez EUREF [9].

\section{Wnioski}

Mammografia jest bardzo wymagającą procedurą obrazowania, zarówno pod względem kompetencji personelu, jak i wydajności sprzętu. Na przestrzeni lat nastąpił znaczny postęp w technologiach wykorzystywanych w obrazowaniu. Obecnie coraz szerzej stosowaną wysokospecjalistyczną techniką obrazowania w mammografii jest tomosynteza. Ze względu na jej wysoki stopień zaawansowania technologicznego nawet niewielkie zmiany w wydajności aparatu mogą prowadzić do zmniejszenia czułości mammografii. W związku z tym należy zwrócić szczególną uwagę na kontrolę jakości urządzeń stosowanych w mammografii 3D z tomosyntezą, która pozwala zapewnić wysoką jakość badań obrazowych oraz bezpieczeństwo pacjentów w trakcie wykonywania tych badań.

\section{Konflikt interesu/ Conflict of interest}

Nie występuje / None 


\section{Etyka/ Ethics}

Treści przedstawione w artykule są zgodne z zasadami Deklaracji Helsińskiej, dyrektywami EU oraz ujednoliconymi wymaganiami dla czasopism biomedycznych.

\section{Piśmiennictwo / References}

[1] Pisano ED, Gatsonis C, Hendrick E i wsp. Diagnostic performance of digital versus film mammography for breast-cancer screening. N Engl J Med 2005; 353:1773-1783

[2] Lisowska J, Bobek-Billewicz B, Zadania Narodowego program zwalczania chorób nowotworowych, Zespół w ramach Rady do spraw Onkologii, 2015.

[3] Dhawan AP. Medical Image Analysis. New Jersey: John Wiley \& Sons; 2011.

[4] Bland KI, Copeland EM, Klimberg VS, Gradishar WJ. The Breast. Elsevier, 2018.

[5] Miller ER, McCurry EM, HruskaB. An Infinite numer of laminograms from a finite numer of radiographs. Radiology 1971;98:249-255.

[6] Komans DB. Development and clinical evaluation of tomosynthesis for digital mammography. Maryland: US Army Medical research and Materiel Command; 2000.

[7] Bushberg J, Seibert J, Leidholdt E, Boone J. The Essential Physics of Medical Imaging. Philadelphia: Lippincott Williams \& Wilkins; 2012.

[8] Helvie MA. Digital mammography imaging: breast tomosynthesis and advanced applications. Radiol Clin North Am. 2010;48(5):917-29.

[9] Protocol fot the Quality of the Physical and Technical Aspects of Digital Breast Tomosynthesis Systems. EUREF, 2018.

[10] Rozporządzenie Ministra Zdrowia w sprawie warunków bezpiecznego stosowania promieniowania jonizującego dla wszystkich rodzajów ekspozycji medycznej (Obwieszczenie Ministra Zdrowia z dnia 3 kwietnia 2017 r., Dz.U.2017.884).

[11] Digital Mammography Quality Control Manual. American College of Radiology 2016.

[12] Dance DR, Young KC, van Engen RE. Estimation of mean glandular dose for breast tomosynthesis: factors for use with the UK, European and IAEA breast dosimetry protocols. Phys. Med. Biol. 56 (2011) $453-471$ 